\title{
LIST OF TEXT ILLUSTRATIONS
}

1. The Alaungpaya Dynasty (1752-1885). D. G. E. Hall, A History of South-East Asia (New York, 1956), p. 733

2. The Bangkok Dynasty (1767 to date). Idem, p. $75^{1}$

50

3. Hypothetical Plan of the Four Courts 74

4. Over-all Scheme of Functionalization 115

5. Development of Agricultural Organization 122

6. Salary Career Patterns for Director-Generals 248

7. The Phin-Phao Clique 273

8. The Sarit Clique 275

9. Phibun's Group 276

10. 1932 Promoters 277

11. 1932, 1945, and 1947 (Non-Clique) Promoters 279

12. Linkage Roles 282

13. SC Node (Sawai-Chamnan Y) 284

14. CP Node (Chuang-Prayoon) 285

15. Sunawin Node 286

16. Xuchat Node 287

17. Phin-Phao and Sarit Clique Contacts 290

18. Phao's Board Contacts 293

19. Sarit's Board Contacts 294

20. Board Contacts of Siri and Lamai 295

21. Board Contacts of Chamnan A and Serm 296

22. Patterns of Developmental Change 375 